\title{
The Anti-depressant Activity of Fixed Oil of Phaseolus vulgaris Linn. in Mice
}

\author{
Salma Sabir ${ }^{\mathrm{a}}$, Sadia Ghousia Baig ${ }^{\mathrm{a} *}$, Muhammad Mohtasheem ul Hasan ${ }^{\mathrm{b}}$, Afshan Siddiq ${ }^{\mathrm{a}}$, \\ Salman Ahmed ${ }^{b}$ and Syeda Anum Fatima ${ }^{a}$ \\ aDepartment of Pharmacology, Faculty of Pharmacy and Pharmaceutical Sciences, \\ University of Karachi, Karachi, Pakistan \\ ${ }^{b}$ Department of Pharmacognosy, Faculty of Pharmacy and Pharmaceutical Sciences, \\ University of Karachi, Karachi, Pakistan
}

(received April 26, 2019; revised November 26, 2019; accepted December 12, 2019)

\begin{abstract}
Phaseolus vulgaris Linn commonly known as red kidney bean, it is enriched in protein, carbohydrates and dietary fibres. Beans have nutritional and health benefits and also possess antimicrobial, antihyperglycemic, antioxidant and anticancer activity due to presence of bio-active chemical constituents. The following study was carried out to evaluate the anti-depressant activity of Phaseolus vulgaris fixed oil (PVFO) using forced swim test and tail suspension test in mice. In this study animals assigned into four groups ( $\mathrm{n}=7)$. Group I: Control normal saline ( $2 \mathrm{~mL} / \mathrm{Kg})$, Group II: PVFO I ( $2 \mathrm{~mL} / \mathrm{Kg})$, Group III: PVFO II $(4 \mathrm{~mL} / \mathrm{Kg})$ and Group IV: standard amitriptyline $(10 \mathrm{mg} / \mathrm{Kg})$. The results were significant and indicated the possible anti-depressant role of Phaseolus vulgaris fixed oil.
\end{abstract}

Keywords: Phaseolus vulgaris, fixed oil, anti-depressant, forced swim test, tail suspension test, beans

\section{Introduction}

The remedies based on plants or herbs used from ancient times because the plants are economical. In each era the use of herbal medicine is admired because they meet the criteria for immediate personal need. Herbal and plant based drugs are gaining attention in developing countries for health related products. For the last few decades the demand of herbal medicine in global market is growing vigorously (Rana et al., 2016).

Phaseolus vulgaris Linn also known as red kidney beans are substantial edible seeds, farmed and utilized globally. They have rich source of proteins, starch and dietary fibres. Dry beans also a great source of nutrients and has lots of importance as functional food, contain high content of protein that is why placed in group with fish, meat, eggs and nuts. $100 \mathrm{~g}$ of cooked beans could fulfil $8-10 \%$ of the daily protein requirement. A variety of prebiotics (resistant starch and the fructo-oligosaccharides, stachyose and raffinose) are also present in beans. These compounds have an influence on microbial flora of gastrointestinal tract and gut metabolism, take part in bacterial fermentation process in intestine. In addition to this some minerals and vitamins have been found in dry beans, specifically vitamin B is present in great amounts. All these vitamins are of great importance

*Author for correspondence;

E-mail: sadiaghousiabaig@yahoo.com as involved in DNA synthesis, repair, methylation and serve as co-factor in different reactions. Beans also contain phenolic compounds, tocopherols, unsaturated fatty acids, peptides as well as other constituents. Some valuable biological activities related to chemical constituents of beans have also been reported in literature, which include antimicrobial, anti-hyperglycemic, antioxidant and anticancer activity (Los et al., 2018).

Depression is a mood disorder which involves low mood, loss of interest in routine activities, and self esteem with a miserable state, could lead one to suicidal attempt. Worldwide a large number of population is affected by depression. Nowadays, depression is a common disorder which badly affect on daily life of individuals which also causing disability and mortality. Exact etiology of disease is still unknown but according to preclinical studies one of the major factor is alteration in CNS serotonin activity which can lead to affective disorders. Other neuro transmitter such as Dopamine (DA), nor epinephrine (NE), glutamate (GA), brain derived neurotrophic factor (BDNF) are also involved in depression (Dunlop and Nemeroff, 2007). Depression is managed by various medications. Several antidepressants are available in market but these synthetic drugs are not ideally effective for every patient.

Herbal therapy is highly recommended for depression and most of the patients use herbal drugs for treatment. 
Conventional anti-depressants possess various adverse effects. An experimental study concluded that Phaseolus vulgaris seed extracts have significant anti-depressant activity, which may be linked with presence of tryptophan and omega-3 fatty acids (Devi and Sharma, 2014). The present study is aimed to evaluate the possible anti-depressant effect of fixed oil of Phaseolus vulgaris $\mathrm{L}$.

\section{Materials and Methods}

Plant material and oil extraction. Dry seeds of Phaseolus vulgaris $\mathrm{L}$ were purchased from local market. Sticks, dirt and stones were separated and seeds were crushed and extracted with hexane. Clear light yellow colour oil was obtained.

Chemicals. Amitriptyline (Merck, Germany) and hexane analytical grade (Merck, Germany).

Animals. Adult mice of both sexes weighing around 20-25 g were taken for current study and housed in a controlled environment of $12 \mathrm{~h}$ light and dark cycle at $22-25{ }^{\circ} \mathrm{C}$ temperature, and humidity was kept between $50-60 \%$. Propylene plastic cages were used for housing mice and maximum 5 mice were housed per each cage. Mice were given standard food and given free access to tap water. The experimental protocol was approved by institutional Bioethics committee, Faculty of Pharmacy and Pharmaceutical Sciences on 17th April 2017 (IBCPH 17) and Board of Advanced Studies (BASR), University of Karachi in November 2015. All experiments were performed in accordance with relevant guidelines and regulations.

Anti-depressant activity. Forced swim test. Mice were divided in four groups $(\mathrm{n}=7)$. The animals received different treatments as follows:

Group-I: normal saline ( $2 \mathrm{~mL} / \mathrm{Kg})$; Group-II: fixed oil of Phaseolus vulgaris ( $2 \mathrm{~mL} / \mathrm{Kg})$; Group-III: fixed oil of Phaseolus vulgaris (4 mL/Kg); Group-IV: standard (amitriptyline $10 \mathrm{mg} / \mathrm{Kg}$ ), All test animals were brought from animal house to the laboratory to acclimatize, 1-2 h before starting experiment. All groups were administered respective doses orally. One hour after dose administration mice were put into cylinder filled with water and allowed to swim. The test comprised of total $6 \mathrm{~min}$, in which initial $2 \mathrm{~min}$ considered habituation period and later 4 min observed the immobility showed by mice. Immobility time was recorded manually with the help of stop watch. After 6 min mice were removed from water and dried with soft towel. Each mouse was used once for swimming (Porsolt et al., 1977).

Tail suspension test. Mice were divided in four groups $(\mathrm{n}=7)$. The animals received different treatments as follows:

Group-I: normal saline ( $2 \mathrm{~mL} / \mathrm{Kg}$ ); Group-II: fixed oil of Phaseolus vulgaris ( $2 \mathrm{~mL} / \mathrm{Kg})$; Group-III: fixed oil of Phaseolus vulgaris ( $4 \mathrm{~mL} / \mathrm{Kg})$; Group-IV: standard (amitriptyline $10 \mathrm{mg} / \mathrm{Kg}$ ), All test animals were brought from animal house $1-2 \mathrm{~h}$ before starting experiment to the laboratory to acclimatize with the conditions. All groups were administered respective doses orally. After $1 \mathrm{~h}$ of dose administration mice were individually suspended about $1 \mathrm{~cm}$ from the tip of tail with the help of adhesive tape to the rim of table at a height of $50 \mathrm{~cm}$ above the floor. Mouse was observed carefully for total 6 min. Immobility time during 6 min was recorded manually using stop watch. Each mouse was used once in the experiment (Steru et al., 1985).

Statistical analysis. Data is expressed as mean \pm SEM and statistically analysed by SPSS version 20 . One way ANOVA was used and followed by tukey hsd. $\mathrm{P}<0.05$ was considered significant.

\section{Results and Discussion}

Force swim test. Data of forced swim revealed that PVFO markedly decreased the immobility time. With both doses i.e. $2 \mathrm{~mL} / \mathrm{Kg}$ and $4 \mathrm{~mL} / \mathrm{Kg}$ there is reduction observed in immobility time as compared to control. Amitriptyline used as standard reference, with $10 \mathrm{mg} / \mathrm{Kg}$ dose also reduced the immobility time. The results were found significant at $\mathrm{P}<0.05$ in all cases (Table 1).

Tail suspension test. $\mathrm{PVFO}$ very significantly $(\mathrm{P}<0.001)$ reduced the immobility time with $2 \mathrm{~mL} / \mathrm{Kg}$ dose as

Table 1. Force swim test

\begin{tabular}{lll}
\hline \hline Groups & Dose & Immobility time $(\mathrm{sec})$ \\
\hline Control & $2 \mathrm{~mL} / \mathrm{Kg}$ & $135 \pm 5.13$ \\
PVFO I & $2 \mathrm{~mL} / \mathrm{Kg}$ & $74 \pm 9.06^{* * *}$ \\
PVFO II & $4 \mathrm{~mL} / \mathrm{Kg}$ & $105 \pm 1.85^{*}$ \\
Amitriptyline & $10 \mathrm{mg} / \mathrm{Kg}$ & $106 \pm 5.13^{*}$ \\
\hline \hline
\end{tabular}

Data is expressed as mean \pm standard error of mean (SEM); $\mathrm{N}=7$; Control=Normal saline; $\mathrm{PVFO}=$ Phaseolus vulgaris fixed oil; ***=Very highly significant at $\mathrm{P}<0.001$ as related to control; **=Highly significant at $\mathrm{P}<0.01$ as related to control; $*=$ Significant at $\mathrm{P}<0.05$ as related to control. 
compared to control. Similarly, amitriptyline also showed highly significant $(\mathrm{P}<0.001)$ reduction in immobility time with $10 \mathrm{mg} / \mathrm{Kg}$ dose level. Results showed that fixed oil also reduced immobility time with $4 \mathrm{~mL} / \mathrm{Kg}$ and reduction in immobility is significant at $\mathrm{P}<0.05$ (Table 2).

Table 2. Tail suspension test

\begin{tabular}{lll}
\hline \hline Groups & Dose & Immobility time $(\mathrm{sec})$ \\
\hline Control & $2 \mathrm{~mL} / \mathrm{Kg}$ & $269 \pm 13.50$ \\
PVFO I & $2 \mathrm{~mL} / \mathrm{Kg}$ & $141 \pm 0.86^{* * *}$ \\
PVFO II & $4 \mathrm{~mL} / \mathrm{Kg}$ & $217 \pm 1.08^{* *}$ \\
Amitriptyline & $10 \mathrm{mg} / \mathrm{Kg}$ & $174 \pm 2.97 * * *$ \\
\hline \hline
\end{tabular}

Data is expressed as mean \pm standard error of mean (SEM); $\mathrm{N}=7$; Control=Normal saline; $\mathrm{PVFO}=$ Phaseolus vulgaris fixed oil; ***=very highly significant at $\mathrm{P}<0.001$ as related to control; $* *=$ Highly significant at $\mathrm{P}<0.01$ as related to control; $*=$ Significant at $\mathrm{P}<0.05$ as related to control.

Depression is low mood behaviour characterised by helplessness, misery, apathy, loss of self confidence, lack of interest, along with biological symptoms including psychomotor impairment, sleep disorders, loss of libido and appetite. Depression is considered major after symptoms intensify (Ashok et al., 2014). For treatment of depression different synthetic drugs such as tricyclic anti-depressants (TCAs), selective serotonin re-uptake inhibitors (SSRIs), selective reversible inhibitors of monoamine oxidase A (RIMAs), and specific serotonin-noradrenaline reuptake inhibitors (SNRIs) are available and used clinically (Fava, 2003) but these drugs are associated with serious side effects such as hypotension, sexual dysfunction, cardiac toxicity, increase in body weight, sleep disorders (Park et al., 2005).

Amitriptyline is a tri cyclic anti-depressant that enhances the activity of nor-epinephrine or serotonin or both (Feighner, 1999). In FST the parameter of observing depression is immobility, that is lowered mood behaviour adopted by mice in forced swim test. The overall exposure time comprises of $6 \mathrm{~min}$, in which first $2 \mathrm{~min}$ considered as habituation period and later 4 min was taken as test observation which gives the time duration of immobility (Abelaira et al., 2013). A mouse is considered immobile when it stops swimming and other body movements excluding some necessary movement to keep the head above the level of water. A drug is believed to be anti-depressant that decreases the depressed behaviour by decreasing immobility time. PVFO showed decrease in immobility time as compared to control. PVFO with $4 \mathrm{~mL} / \mathrm{Kg}$ showed similar effect as standard reference amitriptyline exhibited. The anti-depressant effect showed by fixed oil may be due to re-uptake inhibition of nor epinephrine along with serotonin. Lipid content is very low in common beans, which comprised of some important unsaturated fatty acids (Mabaleha and Yeboah, 2004). These unsaturated fatty acids mainly consist of palmitic acid, oleic and linoleic acid (Grela and Gunter, 1995). Omega-3 fatty acid are derived from $\alpha$-Linolenic acid (ALA). Anti-depressant effect of omega-3 fatty acid has been reported previously (Lakhwani et al., 2007). Anti-depressant activity of flax seed fixed oil also has been proved by experimental study. ALA is major fatty acid found in flax seed (Rath and Pardhan, 2012).

Massive quantity of research has done on this topic suggests that increased production of pro-inflammatory cytokines is involved in depression. These cytokines including interleukin-1 beta (IL-1 $\beta$ ), interleukin-2 (IL-2), interleukin-6 (IL-6), interferon-gamma (IF) and tumor necrosis factor-alpha (TNF- $\alpha$ ) can effect central nervous system directly or indirectly. They decrease the availability of neuro transmitter precursors, activate the hypothalamic-pituitaryaxis and alter the metabolism of neuro transmitters and neuro transmitter transporters. Excessive production of IL- $1 \beta$ and TNF- $\alpha$ are related to severe depression (Suarez, 2003). Increase production of cytokines results from psychological stress, trauma, toxins, infection and some other factors. Omega-3 fatty acids have been reported as pro-inflammatory cytokines inhibitors specifically TNF- $\alpha$ and IL-1, but exact mechanism of inhibition is unknown (James et al., 2000). The exact chemical composition of PVFO is still unidentified, may be presence of omega-3 fatty acid in PVFO is responsible for antidepressant activity.

PVFO was also evaluated for anti-depressant activity using tail suspension model of depression. Same as in force swim test immobility time is the criteria for evaluating depression. In TST immobility is described as a static behaviour in which mice do not make any body movement to escapes from hanging and appear totally motionless. Peaceful and calm environment is basic criteria for TST (Uddin et al., 2018). Mice were considered immobile when they hung inactively and completely motionless. A decrease in immobility time is indicating the anti-depressant effect of an agent. PVFO with the dose $2 \mathrm{~mL} / \mathrm{Kg}$ and amitriptyline 
produced very highly significant $(\mathrm{P}<0.001)$ reduction in immobility time as compared to control group. The effect observed with $2 \mathrm{~mL} / \mathrm{Kg}$ dose was better than amitriptyline. PVFO with $4 \mathrm{~mL} / \mathrm{Kg}$ dose also showed a small decrease in immobility time. We can say that antidepressant effect of PVFO is due to presence of omega-3 fatty acid in it. PUFAs are involved in regulating certain processes in central nervous system such as adjusting blood glucose and food consumption as well as these fatty acids take part in process of apoptosis, regulating emotional behaviour, neuro transmission and neuro inflammation. Furthermore, dietary PUFAs (n-3) control various neuro transmitter operations, as well as signal transmission, responsiveness and phospholipid alteration. PUFAs (n-3) are also connected with psychiatric syndromes and required for mental development, avoidance of neuronal death, and the inhibition of neuro inflammation.

Locomotor activity is a sign of mental alertness and decrease locomotion could be interpreted as reduced CNS excitability which is indicative of calmness and sedation (Islam et al., 2015). The decrease in overall locomotion is an indication of sedative activity (Hossain et al., 2016). A drug with sedative effect reduces locomotor activity in open field test which can also be interpreted as lack of curiosity to the novel environment (Moniruzzaman et al., 2015). In the open field study conducted on PVFO $(2 \mathrm{~mL} / \mathrm{Kg}$ and $4 \mathrm{~mL} / \mathrm{Kg})$, it produced calming effect shown by significant decrease in number of boxes crossed (Salma et al., 2018). According to another research anti-depressants Fluoxetine, Imipramine and Venlafaxine reduce the locomotor activity in unfamiliar environment (Kawai et al., 2019). Which support the finding of current study of PVFO and shows anti-depressant activity and decreases locomotor activity.

Conflict of Interest. The authors declare no conflict of interest.

\section{References}

Abelaira, H.M., Reus, G.Z., Quevedo, J. 2013. Animal models as tools to study the pathophysiology of depression. Brazilian Journal of Psychiatry, 35: S112-S120.

Ashok, K.B.S., Lakshman, K., Velmurugan, C., Sridhar, S.M., Gopisetty, S. 2014. Anti-depressant activity of methanolic extract of amaranthusspinosus. Basic and Clinical Neuroscience, 5:11-17.
Devi, M., Sharma, R. 2014. Anti-depressant activity of aqueous extract of Phaseolus vulgaris (black bean) in rodent models of depression. International Journal of Nutrition, Pharmacology, Neurological Diseases, 4: 118.

Dunlop, B.W., Nemeroff, C.B. 2007. The role of dopamine in the pathophysiology of depression. Archives of General Psychiatry, 64: 327-337.

Fava, M. 2003. Diagnosis and definition of treatmentresistant depression. Biological Psychiatry, 53: 649-659.

Feighner, J.P. 1999. Mechanism of action of antidepressant medications. In: Assessing Anti-depressant Efficacy: A Re-examination in Jan, 1998, Phoenix, AZ, US. Physicians Postgraduate Press.

Grela, E.R., Günter, K.D. 1995. Fatty acid composition and tocopherol content of some legume seeds. Animal Feed Science and Technology, 52: 325-331.

Hossain, M.F., Talukder, B., Rana, M.N., Tasnim, R., Nipun, T.S., Uddin, S.N., Hossen, S.M. 2016. In vivo sedative activity of methanolic extract of Stericulia villosa Roxb. leaves. BMC Complementary and Alternative Medicine, 16: 398.

Islam, N.U., Khan, I., Rauf, A., Muhammad, N., Shahid, M., Shah, M.R. 2015. Antinociceptive, muscle relaxant and sedative activities of gold nanoparticles generated by methanolic extract of Euphorbia milii. BMC Complementary and Alternative Medicine, 15: 160 .

James, M.J., Gibson, R.A., Cleland, L.G. 2000. Dietary polyunsaturated fatty acids and inflammatory mediator production. The American Journal of Clinical Nutrition, 71: 343S-348S.

Kawai, H., Iwadate, R., Ishibashi, T., Kudo, N., Kawashima, Y., Mitsumoto, A. 2019. Antidepressants with different mechanisms of action show different chrono-pharmacological profiles in the tail suspension test in mice. Chronobiology International, 1-14.

Lakhwani, L.A.L.I.T., Tongia, S.K., Pal, V.S., Agrawal, R.P., Nyati, P.R.M., Phadnis, P.R.A.D.E.E.P. 2007. Omega-3 fatty acids have anti-depressant activity in forced swimming test in Wistar rats. Acta Poloniae Pharmaceutical, 64: 271-6.

Los, F.G.B., Zielinski, A.A.F., Wojeicchowski, J.P., Nogueira, A., Demiate, I.M. 2018. Beans (Phaseolus vulgaris $\mathrm{L}$.): whole seeds with complex chemical composition. Current Opinion in Food Science, 19: 63-71.

Mabaleha, M.B., Yeboah, S.O. 2004. Characterization 
and compositional studies of the oils from some legume cultivars, Phaseolus vulgaris, grown in southern Africa. Journal of the American Oil Chemist's Society, 81: 361-364.

Moniruzzaman, M., Rahman, A., Ferdous, A. 2015. Evaluation of sedative and hypnotic activity of ethanolic extract of Scoparia dulcis Linn. EvidenceBased Complementary and Alternative Medicine, 2015.

Park, I.Y., Kim, E.J., Park, H., Fields, K., Dunker, A.K., Kang, C. 2005. Interaction between cardiac calsequestrin and drugs with known cardiotoxicity. Molecular Pharmacology, 67: 97-104.

Porsolt, R.D., Le Pichon, M., Jalfre, M.L. 1977. Depression: a new animal model sensitive to antidepressant treatments. Nature, 266: 730.

Rana, J.H., Patel, U.R., Sonia, J.P., Vijay, L., Dhiran, P.S. 2016. Pharmacological Activities of Phaseolus vulgaris: A Review. Pharma Science Monitor, 7: 107-115.

Rath, B.P., Pradhan, D. 2012. Anti-depressant activity of Linum usitatissimum extract. International Journal of Pharmacognostic and Phytochemical
Research, 1: 29-32.

Salma, B.S.G., Hasan, M., Ahmed, S., Fatima, S.A. 2018. The effect of Phaseolus vulgaris L. Fixed oil on the behavioural activity of swiss albino mice. RADS Journal of Pharmacy and Pharmaceutical Sciences, 6: 76-82.

Steru, L., Chermat, R., Thierry, B., Simon, P. 1985. The tail suspension test: a new method for screening anti-depressants in mice. Psychopharmacology, 85: $367-370$.

Suarez, E.C., Krishnan, R.R., Lewis, J.G. 2003. The relation of severity of depressive symptoms to monocyte-associated pro-inflammatory cytokines and chemokines in apparently healthy men. Psychosomatic Medicine, 65: 362-368.

Uddin, M.M.N., Kabir, M.S.H., Hasan, M., Al Mahmud, Z., Bhuiya, N.M.A., Ahmed, F., Hasan, M.R., Hosen, M.T., Alam, M.S. 2018. Assessment of the antioxidant, thrombolytic, analgesic, anti-inflammatory, anti-depressant and anxiolytic activities of leaf extracts and fractions of Tetracera sarmentosa (L.) Vahl. Journal of Basic and Clinical Physiology and Pharmacology, 29: 81-93. 